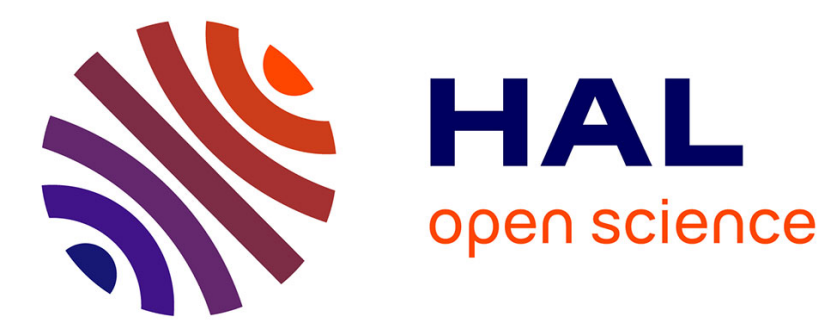

\title{
Organization of the production of sterile medical devices
}

Maria Di Mascolo, Alexia Gouin, Khanh Ngo Cong

\section{To cite this version:}

Maria Di Mascolo, Alexia Gouin, Khanh Ngo Cong. Organization of the production of sterile medical devices. INCOM'06, Apr 2006, France. pp.35. hal-00112836

\section{HAL Id: hal-00112836 \\ https://hal.science/hal-00112836}

Submitted on 9 Nov 2006

HAL is a multi-disciplinary open access archive for the deposit and dissemination of scientific research documents, whether they are published or not. The documents may come from teaching and research institutions in France or abroad, or from public or private research centers.
L'archive ouverte pluridisciplinaire HAL, est destinée au dépôt et à la diffusion de documents scientifiques de niveau recherche, publiés ou non, émanant des établissements d'enseignement et de recherche français ou étrangers, des laboratoires publics ou privés. 


\title{
ORGANIZATION OF THE PRODUCTION OF STERILE MEDICAL DEVICES
}

\author{
Maria Di Mascolo, Alexia Gouin, Khanh Ngo Cong
}

\author{
Laboratoire d'Automatique de Grenoble \\ ENSIEG - Domaine Universitaire - B.P.46 - 38402 St Martin D'Hères Cedex-France \\ Email : Maria.Di-Mascolo@lag.ensieg.inpg.fr,.Alexia.Gouin@lag.ensieg.inpg.fr, \\ Cong-Khanh.Ngo@lag.ensieg.inpg.fr
}

\begin{abstract}
The sterilization of medical devices in hospitals takes an important place in the fight against infections. We propose a simulation model of a real sterilization service. Our aim is to study the impact of smoothing the arrival of medical devices at the sterilization service on the performance of the system. We show that modifying this arrival process significantly improves the performance of the system. Copyright (C) 2006 IFAC
\end{abstract}

Keywords: modelling, simulation, flow optimization, smoothing of arrival process, centralised sterilization.

\section{INTRODUCTION}

Today French hospitals are faced with many challenges such as the reduction of the working time (which implies important reorganizations) and the fight against the nosocomial infections. In addition, the last French hospital regulations introduced economic criteria into the choices and the orientations of the hospital policies. From now on, the objective of ensuring a better quality and safety of medical care go hand in hand with the objective of controlling the expenditure of health. In some services, this control requires an evolution of the organization. This paper is interested in a transverse service: the sterilization. It is an essential activity for the good realization of medical care and examinations which proves to be expensive and constraining.

Generally, the sterilization of the medical devices (or MDs) in health establishments is essential for the fight against infections. It consists in eliminating or killing the micro-organisms carried by contaminated inert media.

Sterilization is sometimes difficult to carry out since the establishments must take into account economic criteria (material, premises, staff, organization) and conditions of feasibility (closeness, time, organization, logistics). Thus, some establishments can ensure the quality of the sterile medical devices thanks to the externalisation of sterilization (Bardet, 2003). This paper deals with the activities of sterilization carried out internally, in a centralised service.

In a process of sterilization, most of the "finished products" (sterile medical devices) are re-injected in the process of sterilization after use in the operating room. If we integrate the use step, the process of sterilization becomes a loop of sterilization (Fig. 1).

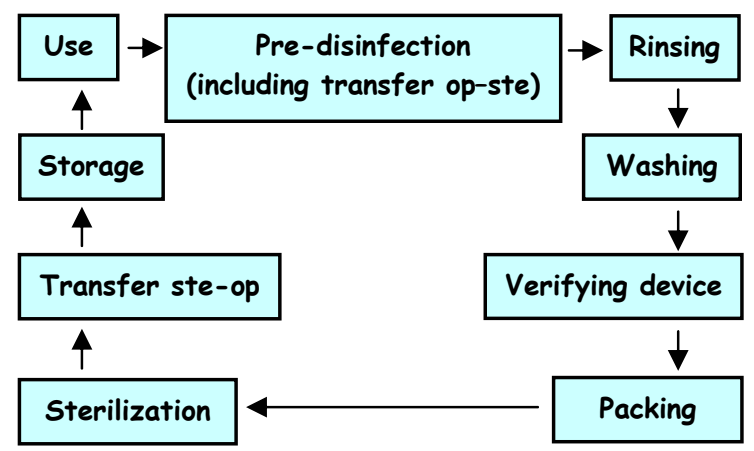

Fig. 1. Loop of sterilization.

The purpose of the pre-disinfection step is to decrease the population of micro-organisms on the soiled equipments, to facilitate the futur washing, and 
to protect the staff during the manipulation (see (standard AFNOR, 2005) for more details). It is imperative to avoid the drying of stains on the equipment. It is realized as close as possible to the place of use. The rinsing does not always exist in the services. The washing aims at eliminating stains (action of a cleaner conjugated to a mechanical action) to obtain a functional and clean medical device. After the washing, the cleanliness of the medical device components should be checked to ensure that no deterioration may affect its security, its integrity or its good functioning. The packing is made as fast as possible after the washing, it constitutes an impervious barrier to micro-organisms. The arrangement of devices in the packaging should allow the good penetration of the sterilizing agent and an aseptic extraction of each sterile medical device. The sterilization is generally made by saturated steam. Physico-chemical and microbiological indicators are used to ensure the good progress of the cycle of sterilization. The transfer "op-ste", which is done during the predisinfection step, corresponds to the transfer of MDs used from operating rooms down to the sterilization service. The transfer "ste-op" corresponds to the transfer of sterile MDs from the sterilization service up to storage area close to operating rooms.

In hospitals the sterile medical devices are packed in containers and bags. A container can consist of one or several medical devices. Reymondon and Marcon (2005) define two solutions: "a container for each intervention" and "a container for each medical device". Thanks to the methodology of group technology and the simulated annealing method, they look for a hybrid solution of grouping the medical devices in containers allowing to reduce the costs (of stocking and process). The private hospital Saint Martin of Caen (France), which is used as a support to the work presented in this paper, also uses a hybrid solution of grouping, and each container and bag containing MDs used in the operating room has a bar code allowing to follow it in each step of the sterilization process.

Note that there are very few papers dealing with the sterilization in the literature. They usually focus on the sterilization process and on the rules which should be respected in order to insure the sterility of the MDs. See (Rutala and Weber, 2004) for example. We are interested here in improving the organization of the production of sterile MDs. Indeed, even if the functioning of the studied service of sterilization appears rather satisfactory to its responsibles, we noted a few points that could be improved: for example, besides the problem of the chronic urgency, related to the insufficient number of specimens, some containers arrive incomplete in the operating rooms. This problem of containers composition can find its explanation in the fact that the workload is not regularly distributed in the course of the day. To smooth the workload, two ways can be planned: either to improve the logistic aspect (by modifying the planning of the staff or the management of queues) or to improve the creation of flow (by modifying either the planning of the interventions or the pre-disinfection and transfer "op-ste" step). The other problem which can be raised is the duration of pre-disinfection. The ideal duration of predisinfection is about 15 minutes. If the majority of the containers have an acceptable pre-disinfection duration, we will see in section 2 that some of the MDs soak in the pre-disinfecting product more than 50 minutes. It is necessary to avoid such a long predisinfection because the disinfecting product attacks the material and thus causes a premature ageing.

In this paper, we chose to focus on the step of predisinfection. On the one hand, the aim is to reduce the number of containers soaking more than 50 minutes and, on the other hand, to better distribute the workload during the day. The remainder of this paper is organized as follows: section 2 studies the pre-disinfection and transfer "op-ste" step between operating rooms and sterilization, section 3 describes the modelling step, section 4 presents the obtained results, and section 5 presents some conclusions.

\section{TRANSFER FROM OPERATING ROOMS DOWN TO STERILIZATION SERVICE}

As our aim is to improve the performance of the system by modifying the transfer from operating

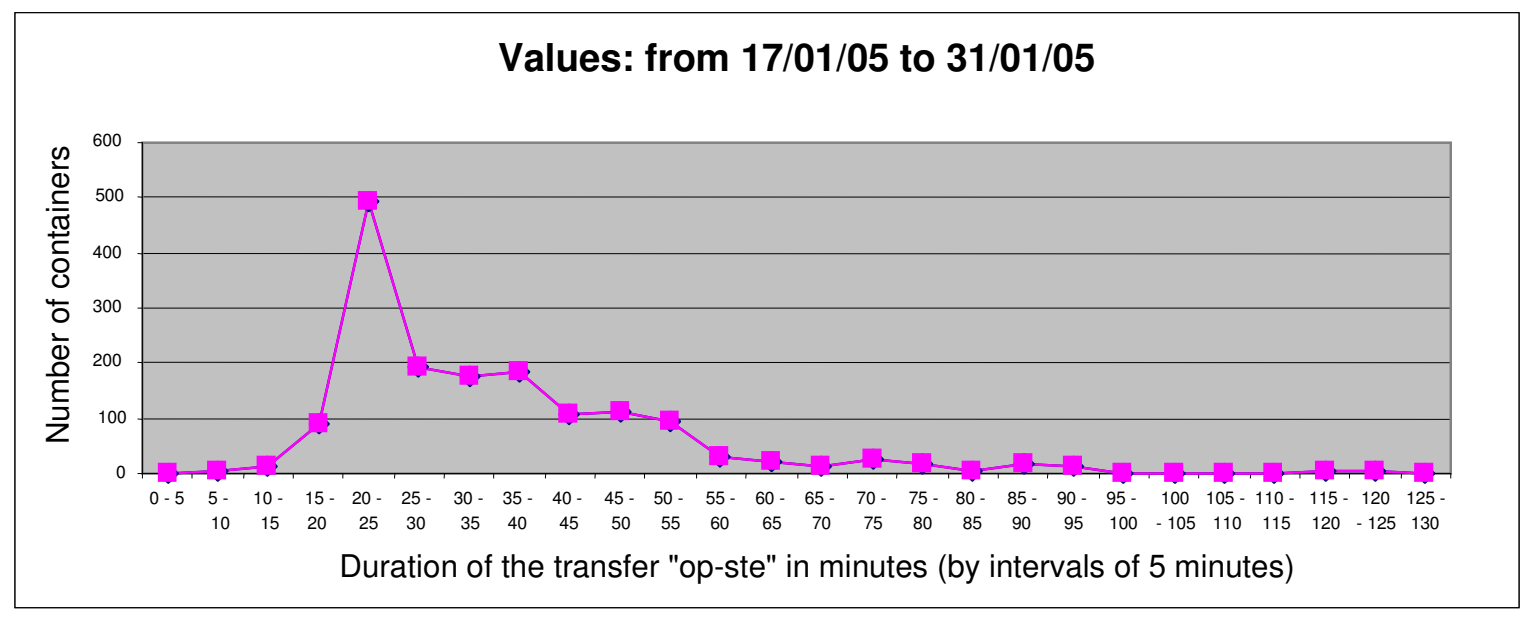

Fig. 2. Duration of the transfer "op-ste". 
rooms down to the sterilization service, we present here some characteristics of this transfer in the private hospital Saint Martin in Caen. We use real data taken from documents called "linking forms" that are used to transmit information between the operating rooms and the sterilization service.

From all the linking forms, we calculate the values for the duration of the transfer "op-ste" as being the time of arrival in the sterilization service minus the time of the beginning of pre-disinfecting. Figure 2 illustrates the number of containers having the same transfer duration (intervals of 5 minutes), as function of the duration of transfer.

The transfer "op-ste" is a part of the pre-disinfection step since the MDs stay into the pre-disinfecting product in the sterilization service until their rinsing. The average duration for the transfer is 28.61 minutes and the variance is 302.5 . This duration can not be too long. The maximum accepted value is 50 minutes for the pre-disinfection since the chemical products used during this step can damage the MDs. We propose solutions to reduce transfer "op-ste" duration in order to get the pre-disinfection step as close as possible to the ideal value which is 15 minutes.

On figure 3, we can see the number of containers for which the transfer was longer than a given value $(15$, $20,30,40,50,60$ or $70 \mathrm{~min})$. We can notice that around $15 \%$ of the containers have a transfer duration greater than 50 minutes.

With our model, our aim will be to study the impact of smoothing the arrival of MDs at the sterilization service on the performance of the system (especially, the number of MDs soaking more than 50 minutes and the sojourn time in the sterilization service, i.e. the time between the beginning of the predisinfecting step and the end, when the MD is available again for a new surgical operation).

\section{MODELLING}

The organization of the sterilization process at the studied hospital can be represented by the model of figure 4. Note that there are 14 operating rooms corresponding to the "use" step. One single person is in charge of the "rinsing" of the medical devices. In the "washing" step, some devices for micro surgery are washed by hand. There are several persons (the number varies during the day) working in the "packing" step. The "autoclave" is the machine which enables the sterilization of the MDs.

From this scheme we build a model with ProModel simulation software. The aim of this simulation model is to improve the performance of the sterilization service, by testing several scenarii for the input parameters of the system, and comparing the performance of the system obtained for each scenario.

In order to do that, we need a model which is as close as possible to the real organization. At the input of the model, we use real data. Other data are estimated from information coming from the hospital data base. Then, we validate this model according to several criteria, such as the number of washing machine cycles, the number of autoclave cycles, the sojourn time, ... Finally, we modify the input data of the system (we keep the time of the beginning of predisinfection and we change the time of the end of the pre-disinfection).

\subsection{Description of the model}

ProModel model is shown in figure 5. At the input of the model, upstream the washing machines, the entity which moves in the model is called "operation". It represents the set of containers and bags used for one given surgical operation. The choice of this entity enables to ensure that all the containers and bags used for a given surgical operation are washed together, in the same washing machine. Downstream the washing machines each "operation" is divided in some containers and bags, whose quantity depends on the operation.

After their use for a surgical operation, the MDs are put in recipients on trolleys, for the pre-disinfection

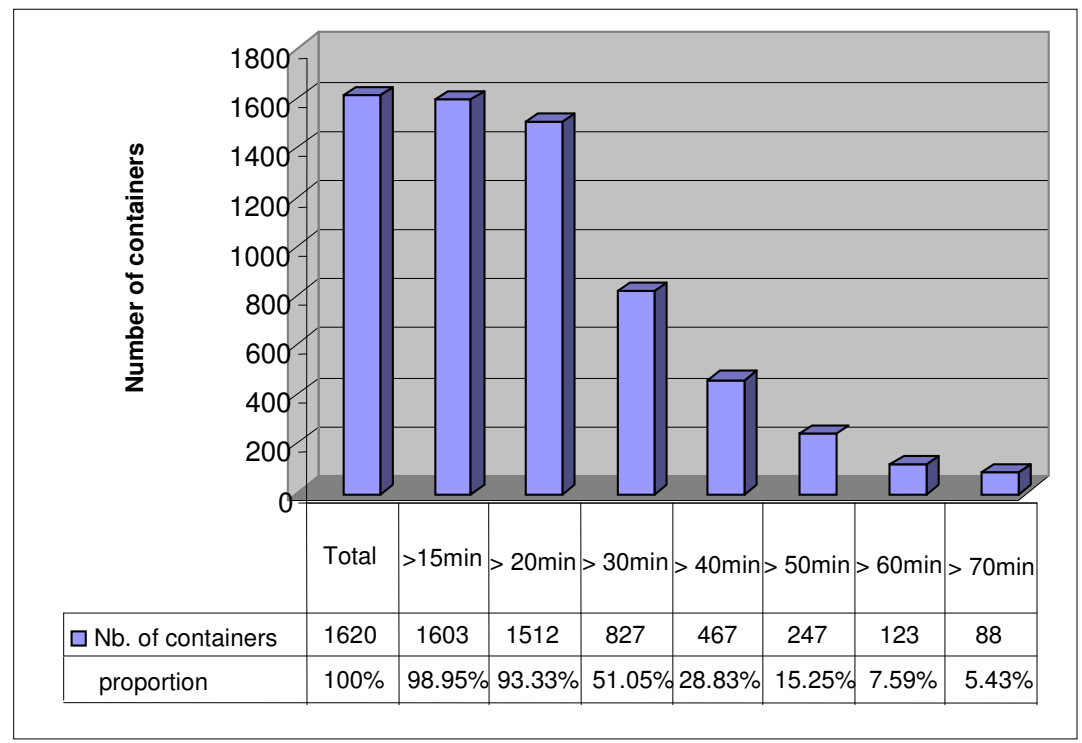

Fig . 3. Number of containers whose transfer "op-ste" is longer than 15, 20, 30, 40, 50, 60, 70 minutes. 


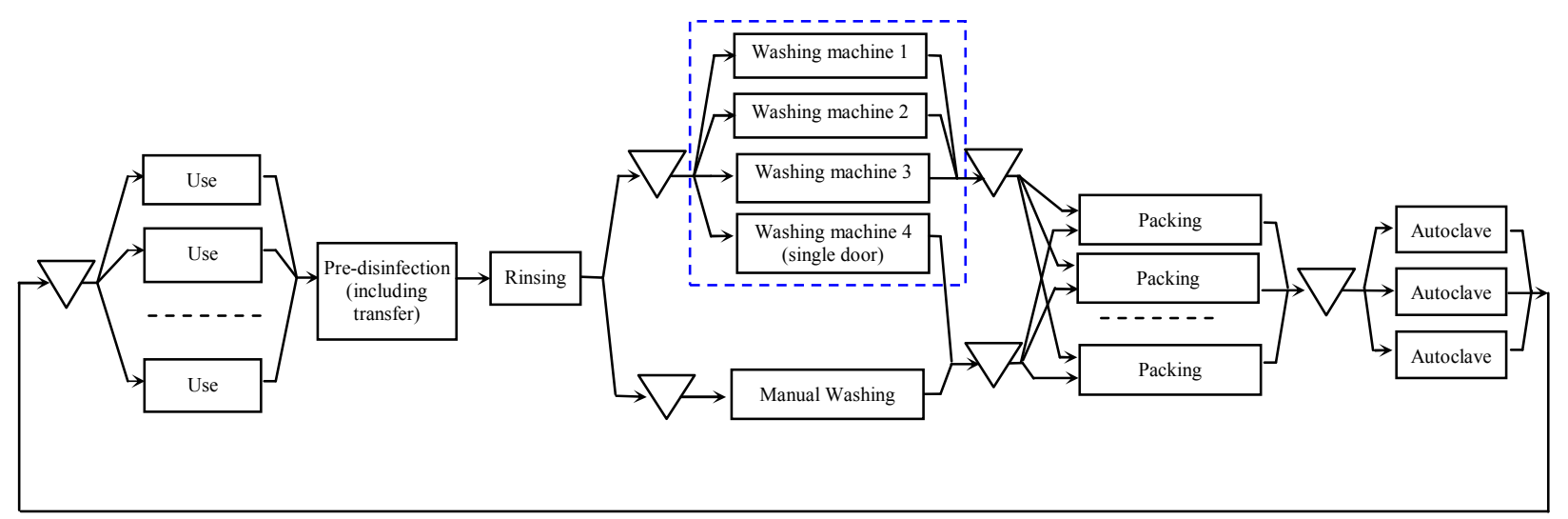

Fig. 4. Organization of the sterilization process in the private Hospital Saint Martin in Caen.

step. Then, these trolleys are transferred to the sterilization service by one employee of the operating theatre suite. In our model, this is represented by an "operation" entity arriving at a place called "trolley". There, the MDs wait in a buffer until the end of the pre-disinfection step (at least 15 minutes), and then wait until the person doing the rinsing is available. The data we have are the time of the beginning of the pre-disinfection step, and the time of the arrival in the sterilization service. After the rinsing step, the "operations" are transferred to the buffer for the washing, before being loaded in a washing machine, which is chosen randomly. The machine starts the washing only when its capacity is reached.

After the washing step, the "operations" are divided in containers and bags, whose quantity depends on the operation. The containers are put in the buffer for containers packing, while the bags are put in the buffer for the bags packing. There are four work stations for the containers packing, each with one operator. One single person is in charge of the bags packing and the sterilization. Bags are grouped in batches of 6 bags. Then, the containers and the batches of bags are transferred to the buffer for sterilization and are considered as entities called "equivalent containers" (one container is equivalent to six bags) that are put in the autoclave. The autoclave begins its processing when its capacity is reached. At the end of the sterilization, the sterilized containers and bags are grouped in the final buffer and leave the system.

\subsection{Required data}

At the input of the model, we use real data taken from linking forms. These data are the beginning time for the pre-disinfection for each "operation", the arrival time of each "operation" at the sterilization service, and the constitution of the "operation" (number of containers and bags in each "operation").

The other data that are needed for ProModel software are calculated thanks to information coming from the data base of the hospital. We used data collected during two weeks: from $1 / 17 / 2005$ to $1 / 28 / 2005$.

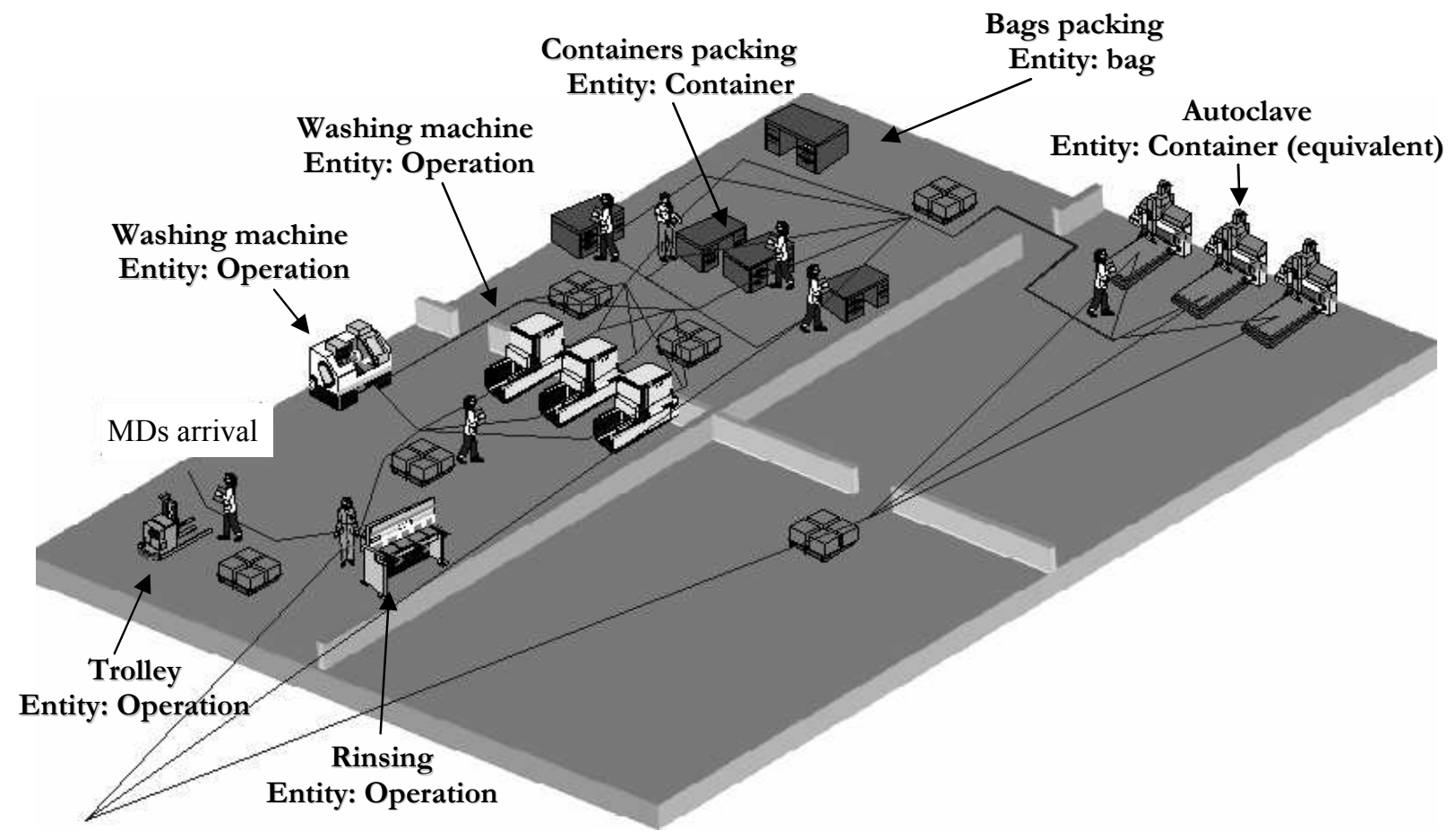

Fig. 5 Model of the sterilization process. 
Table 1. Data used in the model

\begin{tabular}{|c|c|c|}
\hline & Capacity & Average duration \\
\hline Rinsing & 1 operation & $8 \mathrm{~min} / \mathrm{op}$ \\
\hline $\begin{array}{l}\text { Washing } \\
\text { machines }\end{array}$ & 4 operations & $60 \mathrm{~min} / \mathrm{cycle}$ \\
\hline $\begin{array}{l}\text { Containers } \\
\text { packing }\end{array}$ & 1 container & $\begin{array}{l}\text { Normal distribution: } \\
\text { Average: } 21.2 \mathrm{~min} / \text { cont. } \\
\text { Standard deviation: } 3.16\end{array}$ \\
\hline $\begin{array}{l}\text { Bags } \\
\text { packing }\end{array}$ & 1 bag & $1 \mathrm{~min} / \mathrm{bag}$ \\
\hline Autoclave & $\begin{array}{l}10 \text { equivalent } \\
\text { containers }\end{array}$ & $105 \mathrm{~min} /$ cycle \\
\hline
\end{tabular}

We thus estimate the capacity of each working process, the duration of each step (which is deterministic, except for the containers packing), and we take into account the staff planning (see (Ngo Cong, 2005), for details). We obtain the data presented in table 1 .

\subsection{Validation of the model}

For the validation step, we compare the results obtained by our simulation model to the real data. Table 2 shows the values (in minutes) obtained for the sojourn time (the time spent by the MD between its arrival in the sterilization service, and the end of its sterilization in the autoclave). We can note that the sojourn time is well estimated by our model, especially when we cumulate the results for the two weeks.

\section{Table 2. Validation for the sojourn time}

\begin{tabular}{l|ccc} 
Period & Week 1 & Week 2 & Weeks 1+2 \\
\hline Real average sojourn time & 518 & 449 & 483,5 \\
Simulated average sojourn time & 494,9 & 473,4 & 484,2 \\
\hline
\end{tabular}

We also compared the values we obtained for the number of cycles for the washing machines and the autoclaves (see figure 6 for the washing machines).

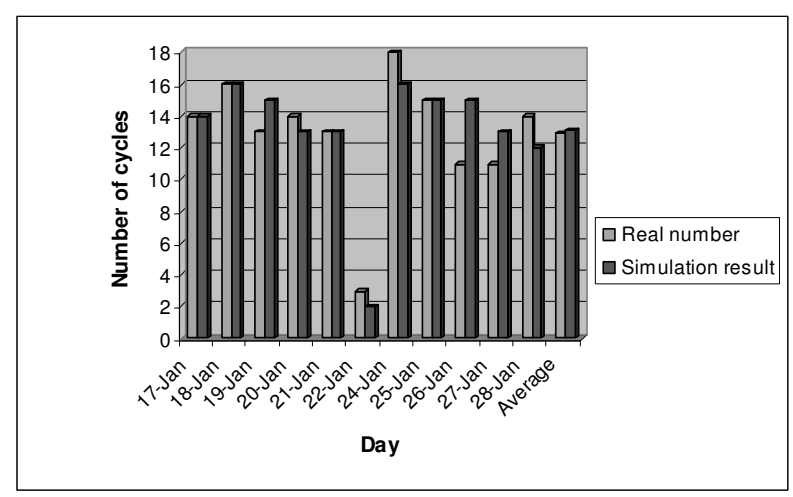

Fig. 6. Comparison between the real number of cycles of the washing machines and the number obtained by simulation.
Once again, we can notice that the simulated results match the real ones. We can thus use our model to improve the performance of the sterilization service.

\section{RESULTS}

We focus on the pre-disinfection step. We are trying to reduce the number of MDs that soak too long, and to smooth the arrival of containers. In the studied sterilization service, the containers enter the sterilization service "randomly". They are transferred when the employee has time, but no control policy is applied. Our idea is to set up a periodic transfer of the trolleys from the operating rooms down to the sterilization service. That is to say, we ask an employee of the operating theatre suite to move all the trolleys containing dirty MDs up to the hoist each $\mathrm{x}$ minutes. This policy is simulated for four different values of $\mathrm{x}$ : 40 minutes, 35 minutes, 30 minutes and 20 minutes, and we present the impact of this policy on the sojourn time (given in minutes), on the duration of the pre-disinfection step (given in minutes) and on the number (or proportion) of operations soaking more than 50 minutes (see table 3 ). Even if our aim is to reduce the soaking duration, we cannot ask the employee to ensure the transfer too often because he / she has other things to do (it is only a part of his / her job). In table 3 we also suppose (see last line) that each trolley is transferred to the sterilization service as soon as the predisinfection step starts. It is the ideal case, but it is rather difficult to set up. Remember that when a trolley enters the sterilization service, it goes to a buffer, and it will leave this buffer when the duration of the pre-disinfection step is greater or equal to 15 minutes and as soon as the person doing the rinsing is available to rinse it. The first line of table 3 (called "current situation") corresponds to a simulation realized with the current organisation of this private hospital (we use the data of the linking forms to know when an "operation" enters the sterilization service). With a periodic transfer, we see that even if the length of time is important (40 minutes) we improve all results: for the sojourn time we win around 30 minutes, for the pre-disinfecting duration we win around 8 minutes and the proportion of "operations" soaking more than 50 minutes is better, compared to the current situation. The best case is for 20 minutes but if the employee transfers the trolley each 30 minutes the average duration of the predisinfection step is lower than 30 minutes.

\section{CONCLUSION}

We observed that in many sterilization services things are done out of habit, and the control policies used in production systems are rarely used. With this paper we wanted to show that some performances of sterilization services can be significantly improved when we use some tools from the production systems. 
$\underline{\text { Table 3. Results }}$

\begin{tabular}{c|cccccc} 
& $\begin{array}{c}\text { Sojourn } \\
\text { time } \\
\text { week } \mathbf{1}\end{array}$ & $\begin{array}{c}\text { Sojourn } \\
\text { time } \\
\text { Week 2 }\end{array}$ & $\begin{array}{c}\text { Sojourn } \\
\text { time } \\
\text { Weeks } \\
\mathbf{1 + 2}\end{array}$ & $\begin{array}{c}\text { Duration of } \\
\text { the pre- } \\
\text { disinfection } \\
\text { step }\end{array}$ & $\begin{array}{c}\text { Number of } \\
\text { operations } \\
\text { soakink more } \\
\text { than 50min }\end{array}$ & $\begin{array}{c}\text { Proportion of } \\
\text { operations } \\
\text { soaking more } \\
\text { than 50 min }\end{array}$ \\
\hline Current situation & 494.9 & 473.4 & 484.2 & 44.67 & 156 & 28.47 \\
Period of 40min & 475.1 & 435.5 & 455.3 & 36.56 & 87 & 15.88 \\
Period of 35min & 473.9 & 434.6 & 454.3 & 33.31 & 55 & 10.04 \\
Period of 30min & 473.5 & 434.4 & 454.0 & 29.36 & 39 & 7.12 \\
Period of 20min & 473.2 & 434.7 & 454.0 & 27.33 & 31 & 5.66 \\
Immediate transfer & 473.2 & 434.6 & 453.9 & 27.27 & 30 & 5.47 \\
\hline
\end{tabular}

In this paper we present a work done in collaboration with a private hospital. This work is a part of a largest work which consists of a study and a comparison between current practices in centralised sterilization services on the one hand, and improvement of their production organization, by using flow control policies, on the other hand.

Acknowledgements : We would like to thank the private hospital Saint Martin in Caen, and especially L. Schwob and F. Leroyer for giving us all the data used in the study and for answering our questions. We thank G. Pasquier for English improvement.

\section{REFERENCES}

Bardet, E. (2003). Externalisation de la stérilisation : conditions de mise en oeuvre, avantages, inconvénients, Mémoire de l'école nationale de la santé publique.

Ngo Cong, K. (2005). Etude de l'organisation de la production de matériels stériles, Mémoire de Master recherche, INPG, Laboratoire d'Automatique de Grenoble.

Reymondon, F and E. Marcon (2005). Optimization of the hospital sterilization costs acting on grouping choices of medical devices into packages using the simulated annealing method, In: IESM'05, International Conference on Industrial Engineering and System Management, 16-19 May 2005, Marrakech, Maroc.

Rutala, WA and DJ Weber (2004). Disinfection and sterilization in health care facilities: What clinicians need to know. Clinical infectious diseases, 39 (5), 702-709.

Standard AFNOR FD S98-135 (2005). Stérilisation des dispositifs médicaux - Guide pour la maîtrise des traitements appliqués aux dispositifs médicaux réutilisables. 